\title{
KELIMPAHAN DAN KERAGAMAN PLANKTON DI DANAU ARANG-ARANG, JAMBI
}

\author{
Susilo Adjie"), Samuel"), dan Subagdja")
}

\begin{abstract}
ABSTRAK
Pengamatan kelimpahan dan keragaman plankton telah dilakukan di Danau Arang-Arang, Jambi pada Bulan Juli, Agustus, September, November, dan Desember tahun 2000 dengan menetapkan 4 stasiun pengamatan yaitu inlet, tengah, outlet, dan hutan rawa. Penelitian ini bertujuan untuk mengetahui kelimpahan dan keragaman plankton dalam kaitannya dengan kesuburan perairan. Hasil pengamatan menunjukkan bahwa plankton yang ditemukan terdiri dari delapan kelas yaitu: Bacillariophyceae (6 genera), Chlorophyceae (15 genera), Cyanophyceae (2 genera), Dinophyceae (1 genus), Euglenophyceae (2 genera), Cladocera (2 genera), Copepoda (1 genus), Monogonanta (1 genus), dan Eubranchiopoda (1 genus). Bacillariophyceae dan Chlorophyceae menempati proporsi yang tertinggi berdasarkan jumlah individu. Danau Arang-Arang termasuk perairan yang kesuburannya rendah (oligotrofik) dengan kelimpahan tertinggi pada bulan September hanya sekitar 506 individu/liter.
\end{abstract}

\section{ABSTRACT: Abundance and diversity of planktons at Arang-Arang Lake, Jambi. By: Susilo Adjie, Samuel, and Subagdja}

A study on abundance and diversity of plankton was conducted at Lake Arang-Arang, Jambi on July, August, September, November, and December 2000 on 4 stations including the inlet, medium, outlet and swampy forest of the lake. The purpose of this study was to know the abundance and diversity of plankton in relation with the productivity of the waters. The results show that plankton of the Lake Arang-Arang consisted of 8 classes, i.e., Bacillariophyceae (6 genera), Chlorophyceae (15 genera), Cyanophyceae (2 genera), Dinophyceae (1 genus), Euglenophyceae (2 genera), Cladocera (2 genera), Copepoda (1 genus), Monogononta (1 genus), and Eubranchiopoda (1 genus). Bacillariophyceae and Chlorophyceae were individually dominant plankton. The Arang-Arang Lake was classified as oligotrophic with highest abundance of only 506 individuallitre in September.

\section{KEYWORDS: $\quad$ plankton, abundance, diversity, Arang-Arang Lake}

\section{PENDAHULUAN}

Danau Arang-Arang merupakan suaka perikanan di daerah dataran rendah dalam areal rawa banjiran, yang terletak di Desa Arang-Arang Kabupaten Muara Jambi, Propinsi Jambi. Danau ini sebagian besar dikelilingi oleh hutan rawa (rawang) dan sebagian kecil terdapat perkebunan kelapa sawit. Danau ArangArang mempunyai 5 cabang anak sungai yang berfungsi sebagai daerah penyangga yaitu Sungai Gelam, Sungai Simpang, Sungai Bakung, Sungai Buluran, dan kanal yang menghubungkan Danau Arang-Arang dengan Sungai Kumpeh yang merupakan salah satu anak Sungai Batanghari.

Dalam dunia perikanan, keberadaan plankton terutama fitoplankton merupakan faktor biologi yang penting, karena fitoplankton merupakan bagian mata rantai pertama dalam jaringan makanan di perairan. Di samping itu, kelimpahan plankton dapat juga menjadi indikator tentang kesuburan perairan (Wetzel \& Likens, 1979). Menurut Swingle dalam Muligan (1969) peran fitoplankton dalam dunia perikanan adalah keterlibatannya dalam sistem rantai makanan menuju ke produksi ikan.

\footnotetext{
-) Peneliti pada Balai Riset Perikanan Periaran Umum, Palembang
}

Penelitian ini dilakukan dengan tujuan untuk mengetahui kelimpahan dan keragaman plankton dalam kaitannya dengan kesuburan perairan Danau Arang-Arang, Jambi.

\section{BAHAN DAN METODE}

Pengambilan contoh plankton dilakukan pada Bulan Juli, Agustus, September, November, dan Desember 2000. Stasiun pengambilan contoh sebanyak 4 stasiun, yaitu: stasiun I di daerah inlet, stasiun II di daerah bagian tengah, stasiun III di daerah outlet dan stasiun IV di daerah areal hutan rawa (Gambar 1)

Pengumpulan plankton dilakukan dengan cara menyaring air contoh sebanyak 50 liter ke dalam jaring plankton dengan ukuran mata jaring sebesar 60 $\mu$ yang ditampung dalam botol vial berukuran $25 \mathrm{ml}$ selanjutnya diawetkan dengan larutan formalin $4 \%$.

Analisis plankton dilakukan di laboratorium biologi Balai Riset Perikanan Perairan Umum Palembang dengan menggunakan buku APHA (1980), Pennak 


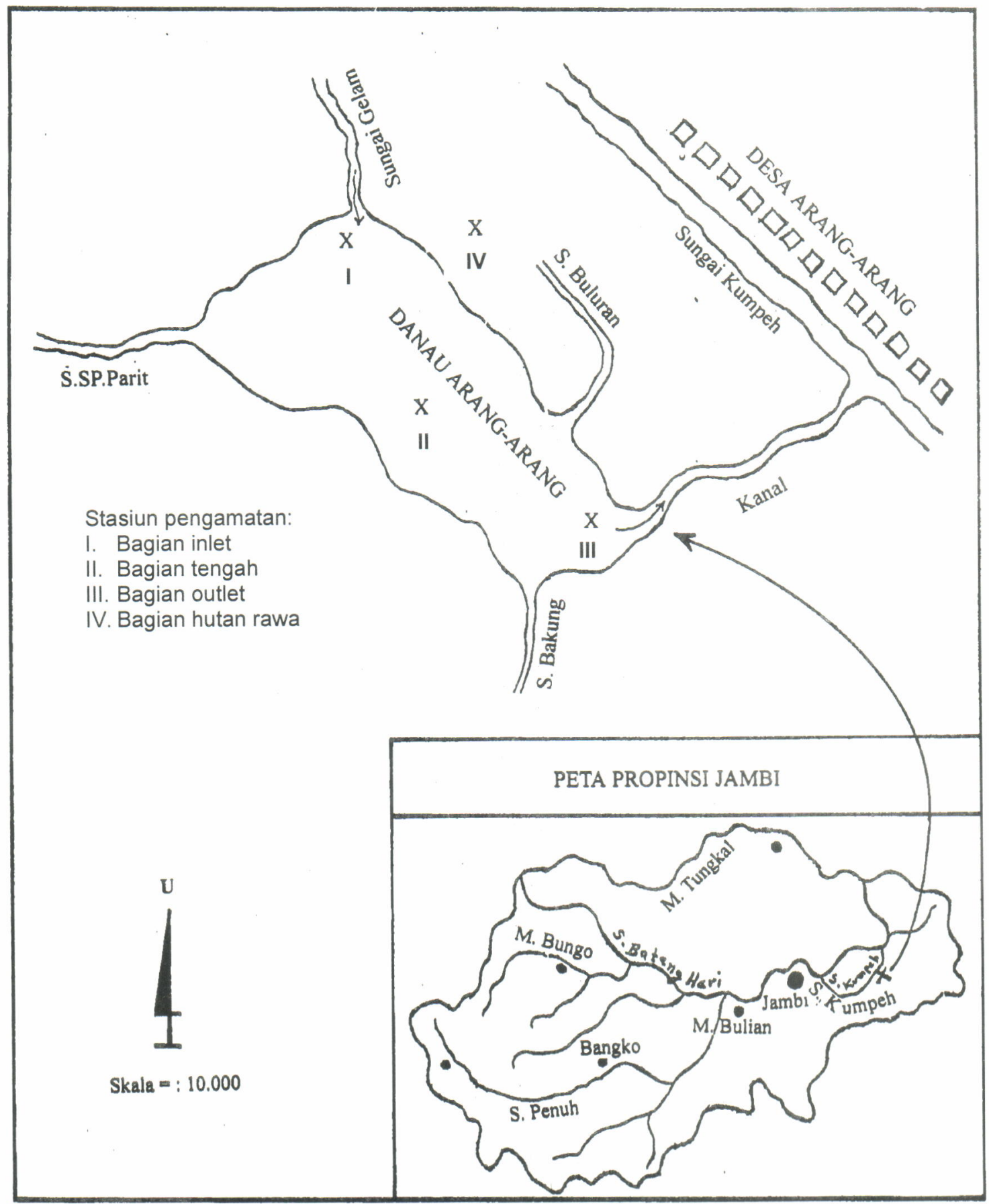

Gambar 1. Posisi pengambilan sampel di Danau Arang-Arang, Jambi.

Figure 1. Sampling position in Arang-Arang Lake, Jambi.

(1978), dan Needham \& Needham (1963). Kelimpahan plankton dihitung menggunakan rumus Sedwick Rafter (Welch, 1952; Edmonson, 1971) yaitu:

$$
N=\text { (ns } \times v a) /(\text { vs } \times v c)
$$

di mana:

$\mathrm{N}$; jumlah individu plankton per liter air contoh ns : jumlah individu plankton pada Sedwick Rafter

va : volume air terkonsentrasi dalam botol vial $(25 \mathrm{ml})$

vs : volume air dalam preparat Sedwick Rafter (1 ml)

vc :volume air contoh yang disaring (50 liter)

Indeks keragaman dihitung berdasarkan rumus 
dari Margalef (1957) dalam Wilhm \& Dorris (1968) yaitu:

$$
d=(s-1) / \operatorname{Ln} N
$$

di mana:

$$
\begin{array}{ll}
\mathrm{d} & \text { : indeks keragaman } \\
\mathrm{N} & \text { : jumlah individu } \\
\mathrm{s} & \text { : jumlah spesies }
\end{array}
$$

Parameter kualitas air yang diamati terdiri dari: suhu, kecerahan, derajat keasaman $(\mathrm{pH})$, oksigen terlarut, alkalinitas total, dan kesadahan total.

\section{HASIL DAN BAHASAN}

Komposisi dan kelimpahan plankton tertera pada Tabel 1, yang terdiri dari 8 kelas yaitu Bacillariophyceae (6 genera), Chlorophyceae (15 genera), Cyanophyceae ( 2 genera), Dinophyceae (1 genus), Euglenophyceae (2 genera), Cladocera (2 genera), Copepoda (1 genus), Monogonanta (1 genus), dan Eubranchiopoda (1 genus). Genera yang sering dijumpai dapat dilihat pada Tabel 2

Genera plankton berkisar antara 9-19 dengan jumlah 219-506 individu/liter. Jumlah individu tertinggi dijumpai pada bulan September yaitu sekitar 506 individu/liter dan didominasi oleh Diatoma dan Cyclotella yang keduanya termasuk ke dalam kelompok Bacillariophyceae (Tabel 1). Apabila dilihat dari proporsi masing-masing kelas (Tabel 3) Bacillariophyceae merupakan kelas plankton yang menempati proporsi tertinggi pada bulan Agustus $(84,60 \%)$ dan September $(83,90 \%)$ dan disusul Chlorophyceae pada bulan Nopember $(56,25 \%)$ serta Desember $(77,53 \%)$.

Bacillariophyceae adalah salah satu kelompok algae yang secara kualitatif dan kuantitatif banyak terdapat di berbagai perairan tipe sungai, baik sebagai plankton maupun sebagai perifiton. Menurut Smith (1950) dan Sachlan (1980) bahwa Bacillariophycea mempunyai sifat kosmopolit, tahan terhadap kondisi ekstrim, mudah beradaptasi, dan mempunyai daya reproduksi yang sangat tinggi.

Kelimpahan dan indeks keragaman plankton di empat stasiun pengamatan selama bulan JuliDesember 2000 disajikan pada Tabel 4. Kelimpahan plankton pada bulan Juli berkisar antara 39-70 individu/liter dengan indeks keragaman 1,56-1,99; pada bulan Agustus antara 12-194 individu/liter dengan indeks keragaman antara $0,90-1,38$, bulan September antara 59-252 individu/liter dengan indeks keragaman 1,09-1,33; bulan Nopember antara 40-215 dengan indeks keragaman 1,52-2,20; dan pada bulan Desember antara 85-145 dengan indeks keragaman 1,29-1,80.
Kelimpahan plankton terendah terdapat di stasiun IV pada bulan Agustus (12 individu/liter) dan kelimpahan tertinggi terdapat di stasiun I pada bulan September (252 individu/liter). Menurut Lander (1978) dalam Biotrop Seameo (1983) kelimpahan plankton demikian dikatagorikan sebagai perairan dengan kesuburan yang rendah atau oligotropik yang ditandai dengan kelimpahan individu alga (kurang dari 2.000 individu/liter). Lebih jauh dikatakan oleh Welch (1952) bahwa perairan oligotropik ditandai dengan kuantitas plankton yang rendah (kurang dari 2.000 individu/liter) dengan jumlah jenis sedikit, jarang terjadi blooming dan biasanya didominasi oleh Chlorophyceae, sedangkan perairan mesotrofik, kuantitas planktonnya cukup banyak (2.000-15.000 individu/liter) dengan jumlah jenis yang lebih bervariasi.

Indeks keragaman plankton terendah terdapat di stasiun III pada bulan Agustus $(0,90)$ dan indeks keragaman plankton tertinggi di stasiun IV pada bulan Nopember $(2,20)$. Keragaman plankton di suatu perairan biasanya dinyatakan dalam jumlah spesies yang terdapat di tempat tersebut. Makin besar jumlah spesies akan makin besar pula keragamannya. Hal ini sesuai dengan Odum (1971) dan Krebs (1985) yang menyatakan bahwa plankton dengan jumlah jenis dan individu terkecil akan didapatkan nilai indek keragaman terkecil pula. Berdasarkan kisaran nilai indeks keragaman plankton $(0,90-2,20)$ maka perairan danau Arang-Arang menunjukkan indikasi kesuburan yang rendah. Canter \& Hill (1979) mengemukakan bahwa rata-rata indeks keragaman plankton yang baik adalah 3 .

Berdasarkan hasil pengamatan terhadap beberapa peubah kualitas air (Tabel 5) terlihat bahwa nilai peubah kualitas air di perairan Danau Arang-Arang menunjukkan kualitas yang rendah.

Nilai derajat keasaman ( $\mathrm{pH}$-perairan) selama penelitian berkisar pada angka 4,5 yang berarti kondisi air bersifat asam. Kondisi perairan seperti ini hanya sesuai untuk kehidupan ikan rawa. Rendahnya nilai $\mathrm{pH}$ tersebut berkaitan dengan rendahnya nilai alkalinitas yang berkisar antara 4,0-12,5 mg/l CaCO3eq. Menurut Hickling (1962) nilai alkalinitas kurang dari 50-200 mg/l $\mathrm{CaCO}_{3}$-eq mengindikasikan tingkat kesuburan perairan yang rendah.

Nilai oksigen pada bulan Juli, September dan Desember tergolong rendah (berkisar antara 2,18$3,36 \mathrm{mg} / \mathrm{l}$ ). Menurut NTAC (1968) dan Pescod (1973), jika pada suatu perairan tidak terdapat senyawa beracun, maka kandungan oksigen terlarut minimum sebesar $2 \mathrm{mg} / \mathrm{l}$ sudah cukup mendukung kehidupan organisme secara normal. Kandungan oksigen terlarut pada bulan Agustus dan Nopember terlihat lebih tinggi (berkisar antara 5,52-6,55 mg/l), karena pemeriksaan dilakukan pada puncak aktivitas fotosintesa dan mungkin hal ini disebabkan aktivitas yang meningkat setelah terjadinya penguraian bahan-bahan organik. 
Tabel 1. Komposisi dan kelimpahan plankton di Danau Arang-Arang, Jambi pada 4 stasiun pengamatan (Juli-Desember 2000)

Table 1. Composition and abundance of plankton at Arang-Arang Lake, Jambi at 4 stations (JulyDecember 2000)

\begin{tabular}{|c|c|c|c|c|c|c|}
\hline \multirow{2}{*}{ No. } & \multirow{2}{*}{$\begin{array}{l}\text { Kelas dan Genus } \\
\text { Class and Genera }\end{array}$} & \multicolumn{5}{|c|}{$\begin{array}{l}\text { Kelimpahan Plankton (individu/liter) } \\
\text { Abundance of Plankton (Individual/litre) }\end{array}$} \\
\hline & & $\begin{array}{l}\text { Juli } \\
\text { July }\end{array}$ & $\begin{array}{l}\text { Agustus } \\
\text { August }\end{array}$ & $\begin{array}{l}\text { September } \\
\text { September }\end{array}$ & $\begin{array}{l}\text { Nopember } \\
\text { November }\end{array}$ & $\begin{array}{l}\text { Desember } \\
\text { December }\end{array}$ \\
\hline$T$ & BACILLARIOPHYCEAE & & & & & \\
\hline 1 & Coscinodiscus & 33 & 6 & 6 & - & - \\
\hline 2 & Cyclotella & 21 & 289 & 150 & 5 & - \\
\hline 3 & Diatoma & - & 119 & 263 & 125 & - \\
\hline 4 & Nitzschia & - & - & - & 15 & - \\
\hline 5 & Stepanodiscus & - & 3 & 3 & - & - \\
\hline 6 & $\begin{array}{l}\text { Synedre } \\
\text { CHLOROPHYCEAE }\end{array}$ & - & 3 & 3 & - & 30 \\
\hline 1 & $\begin{array}{l}\text { Bulbochaeta } \\
\text { But }\end{array}$ & 6 & - & - & - & - \\
\hline 2 & Cladophora & - & 3 & - & - & - \\
\hline 3 & Closterium & 3 & - & - & 5 & - \\
\hline 4 & Cosmarium & - & - & - & 15 & - \\
\hline 5 & Desmidium & 8 & 3 & 3 & 5 & - \\
\hline 6 & Docidium & - & - & - & 5 & - \\
\hline 7 & Gymnozyga & - & - & - & 90 & 30 \\
\hline 8 & Hydrodiction & - & 6 & 6 & - & - \\
\hline 9 & Mougeotia & - & 24 & 38 & 20 & 60 \\
\hline 10 & Polycystis & - & - & - & 5 & - \\
\hline 11 & Spirogyra & - & - & - & 20 & - \\
\hline 12 & Staurastrum & - & - & - & 45 & 140 \\
\hline $\begin{array}{l}13 \\
\text { III }\end{array}$ & $\begin{array}{l}\text { Ulothrix } \\
\text { CYANOPHYCEAE }\end{array}$ & 19 & 6 & 20 & 40 & 50 \\
\hline 1 & Xantidium & - & - & - & 15 & 65 \\
\hline 2 & Zygnema & - & - & - & 5 & - \\
\hline 3 & Anabaena & 39 & - & - & 20 & - \\
\hline 4 & $\begin{array}{l}\text { Tolypothrix } \\
\text { DINOPHYCEAE }\end{array}$ & 5 & - & - & - & - \\
\hline 1 & $\begin{array}{l}\text { Glenodinium } \\
\text { EUGLENOPHYCEAE }\end{array}$ & 3 & - & - & - & - \\
\hline 1 & Euglena & 13 & - & - & . & - \\
\hline$\stackrel{2}{\mathrm{~V} I}$ & $\begin{array}{l}\text { Phacus } \\
\text { CLADOCERA }\end{array}$ & - & - & - & 5 & - \\
\hline 1 & Ceriodaphnia & - & - & - & 5 & 10 \\
\hline $\begin{array}{c}2 \\
\text { VII }\end{array}$ & $\begin{array}{l}\text { Chydorus } \\
\text { COPEPODA }\end{array}$ & 63 & - & - & - & - \\
\hline $\begin{array}{l}1 \\
\text { VIII }\end{array}$ & $\begin{array}{l}\text { Naupllus } \\
\text { MONOCONONTA }\end{array}$ & $=$ & 31 & 11 & 35 & 50 \\
\hline $\begin{array}{c}1 \\
\mid X\end{array}$ & $\begin{array}{l}\text { Brachionus } \\
\text { EUBRANCHIOPODA }\end{array}$ & - & 3 & 3 & - & 10 \\
\hline 1 & Eubranchiopus & 6 & - & - & - & - \\
\hline \multicolumn{2}{|c|}{ Jumlah genera/Number of genera } & 12 & 12 & 11 & 19 & 8 \\
\hline \multicolumn{2}{|c|}{$\begin{array}{c}\text { Jumlah Indlvidu/litor } \\
\text { Number of Ind/vidual/IItre }\end{array}$} & 210 & 469 & 608 & 480 & 446 \\
\hline
\end{tabular}

Nilal kesadahan berklsar antara $3-10 \mathrm{mg} / \mathrm{l}$ $\mathrm{CaCO}_{3-0 q}$ tergolong peralran lunak (soft waters) karena kurang darl $50 \mathrm{ppm} \mathrm{CaCO}_{3}-e q$, hal Inl sesual dengan pernyataan Swingle (1968). Peralran dengan kesadahan kurang darl 12 ppm maka produktlvitasnya rendah hal Inl berpengaruh terhadap lambatnya pertumbuhan Ikan. Oleh karena itu menurut Wardoyo
(1978) dalam budi daya Ikan dl kolam yang alrnya berkesadahan rendah perlu dllakukan pengapuran.

Peralran Danau Arang-Arang dikelilingl oleh hutan rawa dan alrnya berhubungan dengan Sungal Kumpeh, oleh karena litu fluktuasl air danau sangat dlpengaruhl oleh pasang surutnya Sungal Kumpeh. 
Tabel 2. Genera plankton yang dominan dan sering ditemukan di Danau Arang-Arang selama bulan Juli sampai Desember 2000

Table 2. Dominant genera of plankton in Arang-Arang Lake, Jambi during July to December 2000

\begin{tabular}{|c|c|}
\hline Kelas/Class & Genus/Genera \\
\hline Bacillariophyceae & Cylotella dan Diatoma \\
\hline Chlorophyceae & Desmidium, Mougeotia, dan Ulothrix \\
\hline Copepoda & Nauplius \\
\hline
\end{tabular}

Tabel 3. Proporsi (\%) masing-masing kelas plankton di Danau Arang-Arang, Jambi pada bulan Juli sampal Desember 2000

Table 3. $\quad$ Proportion (\%) of each plankton class in Arang-Arang Lake, Jambi during July to December 2000

\begin{tabular}{|c|c|c|c|c|c|c|}
\hline \multirow[b]{2}{*}{ No. } & \multirow{2}{*}{$\begin{array}{l}\text { Kelas } \\
\text { Class }\end{array}$} & \multicolumn{5}{|c|}{ Propors|/Proportion (\%) } \\
\hline & & $\begin{array}{l}\text { Jull } \\
\text { July }\end{array}$ & $\begin{array}{l}\text { Agustus } \\
\text { August }\end{array}$ & $\begin{array}{l}\text { September } \\
\text { September }\end{array}$ & $\begin{array}{l}\text { Nopember } \\
\text { November }\end{array}$ & $\begin{array}{l}\text { Desember } \\
\text { December }\end{array}$ \\
\hline 1 & Bacillariophyceae & 17,00 & 84,60 & 83,90 & 30,21 & 6,74 \\
\hline 2 & Chlorophyceae & 19,00 & 8,50 & 13,32 & 56,25 & 77,53 \\
\hline 3 & Cyanophyceae & 22,00 & - & - & 4,17 & - \\
\hline 4 & Euglenophyceae & 7,00 & - & - & 1,04 & - \\
\hline 5 & Cladocera & 32,00 & - & - & 1,04 & 2,25 \\
\hline 6 & Copepoda & - & 6,30 & 2,18 & 7,29 & 11,23 \\
\hline 7 & Monogononta & - & 0,60 & 0,60 & - & 2,25 \\
\hline 8 & Eubranchiopoda & 3,00 & - & - & - & - \\
\hline
\end{tabular}

Tabel 4. Kelimpahan (individu/liter) dan indeks keragaman plankton pada 4 stasiun pengamatan (Juli, Agustus, September, Nopember, dan Desember 2000)

Table 4. Abundance (individual/litre) and diversity index of plankton at 4 station of observation (July, August, September, November, and December 2000)

\begin{tabular}{|c|c|c|c|c|c|c|c|c|}
\hline \multirow{3}{*}{ Bulan/Month } & \multicolumn{8}{|c|}{$\begin{array}{l}\text { Stasiun } \\
\text { Station }\end{array}$} \\
\hline & \multicolumn{2}{|c|}{1} & \multicolumn{2}{|c|}{ II } & \multicolumn{2}{|c|}{ III } & \multicolumn{2}{|c|}{ IV } \\
\hline & A & DI & A & DI & A & DI & A & DI \\
\hline $\begin{array}{l}\text { Juli } \\
\text { July }\end{array}$ & 39 & 1,56 & 70 & 1,74 & 60 & 1,79 & 50 & 1,99 \\
\hline $\begin{array}{l}\text { Agustus } \\
\text { August }\end{array}$ & 194 & 1,20 & 107 & 1,33 & 183 & 0,90 & 12 & 1,38 \\
\hline $\begin{array}{l}\text { September } \\
\text { September }\end{array}$ & 252 & 1,80 & 101 & 1,32 & 94 & 1,33 & 59 & 1,09 \\
\hline $\begin{array}{l}\text { Nopember } \\
\text { November }\end{array}$ & 1,09 & 1,86 & 40 & 1,90 & 45 & 1,52 & 215 & 2,20 \\
\hline $\begin{array}{l}\text { Desember } \\
\text { December }\end{array}$ & 105 & 1,71 & 85 & 1,80 & 145 & 1,35 & 110 & 1,29 \\
\hline $\begin{array}{c}\text { Keterangan/Lege } \\
\text { A } \\
\text { DI }\end{array}$ & 0 & $\begin{array}{l}\text { Yance } \\
\text { divers }\end{array}$ & & & & & & \\
\hline
\end{tabular}

Pada musim kemarau air Sungai Kumpeh tidak dapat masuk ke dalam Danau Arang-Arang yang menyebabkan kondisi air danau bersifat asam sehingga hanya ikan-ikan yang toleran terhadap air asam saja yang dapat hidup. Namun bila musim hujan air Sungai Kumpeh mengalir ke danau, maka ikanikan sungai yang tergolong ikan putihan (withefish) akan dapat hidup bersamaaan dengan ternetralisirnya keasaman air di danau. Demikian pula areal hutan rawa yang merupakan tumbuhan tegakan berfungsi sebagai tempat ikan-ikan mencari makanan dan berlindung yang sehingga merupakan tempat daerah penyangga untuk memproduksi ikan (Samuel et al., 2002).

Lebih jauh dikatakan oleh Kartamihardja \& Satria (2000) bahwa salah satu tindakan untuk menjaga dan meningkatkan fungsi dan efektivitas suaka yakni dengan pengkayaan makanan alami misalnya dengan penebaran atau introduksi jenis zooplankton seperti Daphnia sp yang telah berhasil dilaksanakan di Waduk Jatiluhur. 
Tabel 5. Kualitas air Danau Arang-Arang, Jambi pada bulan Juli, Agustus, September, Nopember, dan Desember 2000

Table 5. Water quality of Arang-Arang Lake in July, August, September, November, and December 2000

\begin{tabular}{|c|c|c|c|c|c|}
\hline $\begin{array}{c}\text { Parameter } \\
\text { Parameters }\end{array}$ & $\begin{array}{l}\text { Juli } \\
\text { July }\end{array}$ & $\begin{array}{l}\text { Agustus } \\
\text { August }\end{array}$ & $\begin{array}{l}\text { September } \\
\text { September }\end{array}$ & $\begin{array}{l}\text { Nopember } \\
\text { November }\end{array}$ & $\begin{array}{l}\text { Desember } \\
\text { December }\end{array}$ \\
\hline Suhu/Temperature $\left({ }^{\circ} \mathrm{C}\right)$ & $26-27$ & $25-29$ & 26 & $26-27$ & $25-26$ \\
\hline Kecerahan/Transparency $(\mathrm{cm})$ & $50-75$ & $70-85$ & $40-85$ & $70-80$ & $60-80$ \\
\hline $\mathrm{pH}$ (unit) & 4,50 & 4,50 & 4,50 & 4,50 & 4,50 \\
\hline $\mathrm{O}_{2}(\mathrm{mg} / \mathrm{l})$ & $2,18-2,80$ & $5,52-6,55$ & $2,43-3,14$ & $5,67-6,55$ & $3,20-3,36$ \\
\hline Alkalinitas/Alkalinity (mg/l $\left.\mathrm{CaCO}_{3}-\mathrm{eq}\right)$ & $8,5-11,0$ & $5,0-7,5$ & $6,0-7,5$ & $4,0-12,5$ & $8,5-10,0$ \\
\hline Kesadahan/Hardness (mg/l $\left.\mathrm{CaCO}_{3}-\mathrm{eq}\right)$ & $3,0-3,3$ & $4,0-5,0$ & $5,0-5,6$ & $5,0-8,0$ & $5,0-10,0$ \\
\hline
\end{tabular}

\section{KESIMPULAN}

Di Danau Arang-Arang, Jambi selama bulan Juli sampai Desember 2000, ditemukan 8 kelas plankton masing-masing Bacillariophyceae (6 genera), Chlorophyceae (15 genera), Cyanophyceae (2 genera), Dinophyceae (1 genus), Euglenophyceae (2 genera), Cladocera (2 genera), Copepoda (1 genus), Monogonanta (1 genus), dan Eubranchiopoda (1 genus).

Kelompok plankton dari Kelas Bacillariophyceae menempati proporsi tertinggi pada bulan Agustus $(84,60 \%)$ dan bulan September $(83,90 \%)$ serta Chlorophyceae pada bulan Nopember $(56,25 \%)$ dan bulan Desember $(77,53 \%)$.

Danau Arang-Arang ditinjau dari kualitas airnya, dikatagorikan sebagai perairan yang kesuburannya rendah (oligotropik) dengan jumlah individu plankton tertinggi pada bulan September sekitar 506 individu/liter dan indeks keragaman plankton yang rendah $(0,90-2,20)$ serta nilai alkalinitas perairan yang rendah pula $\left(4,0-12,5 \mathrm{mg} / \mathrm{l} \mathrm{CaCO}_{3}\right.$-eq).

\section{SARAN}

Supaya Danau Arang-Arang berfungsi dengan baik dan dapat menjamin kehidupan ikan maka areal hutan rawa yang merupakan tempat ikan-ikan mencari makan dan berlindung agar dipertahankan sebagai daerah penyangga untuk memproduksi ikan.

Perlu adanya pengkayaan makanan alami dengan cara penebaran atau introduksi jenis zooplankton.

\section{UCAPAN TERIMAKASIH}

Ucapan terima kasih disampaikan pada Saudara Gatot Subroto dan Bapak Akrimi sebagai teknisi litkayasa yang telah membantu penelitian ini.

\section{DAFTAR PUSTAKA}

APHA. 1981. Standard method for the examination of water and wastewater. $15^{\text {th }}$ Edition. American Public Health Association, Washington, D.C., 1134 pp.

BIOTROP-SEAMEO. 1983. Penyelidikan tanaman air dan perikanan waduk pada Proyek Irigasi Widas. Biotrop. Bogor, 55 pp.

Canter, L.W., \& Hill L.G. 1979. Hand Book of Variables for Environmental Impact Assessment. Ann Arbor Science Publishers Inc. Mich, 235 pp.

Edmonson, G.G. 1971. Manual and methods for assessment of secondary productivity in freshwater. IBD. Handbook Blackwell Science Publication.Oxford, 209 pp.

Hickling, C.F. 1962. Fish Culture. Faber \& Faber, London. 317 pp.

Kartamihardja. E.S \& H. Satria. 2000. Evaluasi ekologis suaka perikanan Danau Batu Bumbun di Daerah Aliran Sungai Mahakam Tengah dan implikasi Pengelolaannya. Jurnal Penelitian Perikanan Indonesia, 6 (2): 22.

Krebs, J.K. 1985. Ecology the experiment analysis of distribution and abundance. Third Edition. Harper \& Row Publisher. New York. 800 pp.

Muligan, H..F. 1969. Management of aquatic vascular plants and algae. In Eutrofication: Causes, Consequences, and Correctives. Proceedings of Symposium. National Academy of Science, Washington. D.C, p: 464--482.

NTAC. 1968. Water quality criteria. FWPCA. Washington. United of America, 234 pp.

Needham, J.G. \& DR. Needham. 1963. A guide to the study of freshwater biology. $15^{\text {th }}$ Edition. Holden Day Inc. Sanfransisco, $108 \mathrm{pp}$. 
Odum, E.P. 1971. Fundamentals of ecology. Third Edition. W.B. Sounders Company. Toronto. 574 pp.

Pennak, R.W. 1978. Freshwater invertebrate in the United State of America. Mc. Grawhill Book Company. New York, 803 pp.

Pescod, M.B. 1973. Investigation of rational effluent and stream standarts for tropical countries. Asean Institute of Tecnology. Bangkok. $54 \mathrm{pp}$.

Sachlan, M. 1980. Planktonologi. Fakultas Peternakan dan Perikanan UNDIP. Semarang. 103 pp.

Samuel, S. Adjie, \& Z. Nasution. 2002. Aspek lingkungan dan biologi ikan di Danau Arang-Arang,
Propinsi Jambi. Jurnal Penelitian Perikanan Indonesia, 8(1): 1--13.

Smith, G. M. 1950. The fresh-water algae of United States. Second edition. Mc. Graw-Hill Book Company Inc. New York, 719. pp.

Welch, P.S. 1952. Lymnologycal methods. Mc. GrawHill Book Company Ltd. New York, 381 pp.

Wilhm, J.L \& T.C. Dorris. 1968. Biological parameters for water quality criteria. Bio. Science, 18: 447-491.

Wetzel, R.G. \& G.E. Likens. 1979. Limnology analisys. W.B.. Sounders Company. Philadelphia. $367 \mathrm{pp}$. 
